\title{
Peripheral Nerve Stimulation for Neuropathic Pain
}

\author{
Konstantin V. Slavin \\ Department of Neurosurgery, University of Illinois at Chicago, Chicago, Illinois 60612
}

Summary: Peripheral nerve stimulation (PNS) has been used for treatment of neuropathic pain for more than 40 years. Recent resurgence of interest to this elegant surgical modality came from the introduction of less invasive implantation techniques and the wider acceptance of neuromodulation as a treatment of medically refractory cases. This article reviews the literature on the use of PNS for neuropathic pain and describes current indications and hardware choices in frequent use. Published experience indicates that neuropathic pain responds to PNS in many patients. PNS works well in both established indications, such as post-traumatic and postsurgical neuropathy, occipital neuralgia, and complex regional pain syndromes, and in relatively new indications for neuromodulation, such as migraines and daily headaches, cluster headaches, and fibromyalgia. Future research and growing clinical experience will help in identifying the best candidates for PNS, choosing the best procedure and best hardware for each individual patient, and defining adequate expectations for patients and pain specialists. Key Words: Neuromodulation, neuropathic pain, migraine, headache, occipital neuralgia, cluster headache, fibromyalgia.

\section{INTRODUCTION}

Electrical stimulation of peripheral nerves is used in a variety of medical applications. The most common applications include testing neuromuscular conduction in anesthesia and intensive care units ${ }^{1,2}$; motor stimulation of phrenic nerves in cases of diaphragmal palsy ${ }^{3}$ and somatic nerves of the extremities in patients with hemiplegia $^{4,5}$ and paraplegia ${ }^{4,6}$; vagal nerve stimulation for treatment of intractable epilepsy ${ }^{7}$ and refractory depres$\operatorname{sion}^{8}$; autonomic stimulation for urinary ${ }^{9}$ and gastrointestinal disorders ${ }^{10}$; and, finally, the stimulation of peripheral nerve for control of neuropathic pain. ${ }^{11}$

Peripheral nerve stimulation (PNS) has been a part of the neurosurgical armamentarium for a long time. It presents an excellent modality for the treatment of various neuropathic pain conditions and is used to complement the other electrical neuromodulation procedures, namely, spinal cord stimulation (SCS) and deep brain stimulation (DBS). Similar to SCS, PNS is thought to be based on the gate-control theory of pain, suggested by Melzack and Wall more than 40 years ago. ${ }^{12}$ In terms of approved indications, SCS is by far

Address correspondence and reprint requests to: Konstantin Slavin, M.D., Department of Neurosurgery, University of Illinois at Chicago, 912 S. Wood Street, M/C 799, Chicago, IL 60612. E-mail: kslavin@uic.edu. more accepted than PNS, and frequently PNS is considered a novel technique in the continuum of treatment modalities for medically refractory neuropathic pain. This, however, is a misconception. Although the interest in PNS has been increasing over the last few years, the use of electrical stimulation of the peripheral nerves for pain control is anything but new.

When, about 40 years ago, Wall and Sweet tried to find a new approach to suppression of neuropathic pain, they inserted an electrode into their own infraorbital foramina and obtained decrease in pain perception during the entire episode of electrical stimulation. ${ }^{13,14}$ Moreover, the first articles dedicated to the idea of PNS with implantable devices (even before dorsal column stimulation, later known as SCS, was introduced) were published back in 1966 and $1967 .^{13,15}$ In eight patients with neuropathic pain, the stimulation resulted in lasting pain suppression as long as the stimulator was on. ${ }^{13} \mathrm{At}$ about the same time, Shelden ${ }^{15}$ implanted PNS electrodes and stimulated them through an implanted receiver at $14,000 \mathrm{~Hz}$, thereby achieving temporary pain relief.

Over the 20 years that followed, multiple reports appeared in the literature dealing with various applications of PNS, summarizing experience with various types of equipment, and describing different surgical techniques for PNS electrode implantation. The articles that appeared in 1970s, ${ }^{16-21} 1980 \mathrm{~s},{ }^{22-28}$ and $1990 \mathrm{~s}^{29-32}$ mostly 
represented single-institution series with use of different electrodes that had been implanted in the vicinity, or in direct contact with the peripheral nerve-the same nerve that was thought to be responsible for generation of pain either as a result of direct traumatic or iatrogenic injury, or as a part of a complex regional pain syndrome. In most cases, the electrode implantation involved surgical exploration of the peripheral nerve and placement of a flat plate multicontact electrode (a paddle electrode) immediately next to it.

Unfortunately, the reported results of this PNS approach were not extremely encouraging in terms of pain relief. In 1976, for example, Sweet ${ }^{20}$ reported an overall long-term success rate of $25 \%$, and in 1982, Nashold et al. ${ }^{24}$ reported successful outcomes in $53 \%$ of patients with upper extremity nerve implants and only $31 \%$ of patients with sciatic nerve implantation, for a total success rate of less than $43 \%$. In addition, reports of nerve injury from electrode insertion or stimulation-related fibrosis made PNS less attractive, ${ }^{17,33}$ particularly after the SCS approach became universally accepted as a means of long-term treatment of medically intractable neuropathic pain of various etiologies.

A few enthusiastic centers continued using PNS for certain neuropathic pain syndromes, but the lack of wide interest among implanters resulted in little effort on the part of device manufacturers in getting appropriate approval from the U.S. Food and Drug Administration (FDA) for use of their implantable generators in PNS. Even now, according to the manufacturers' manuals, the only device specifically approved for peripheral nerve stimulation is a radiofrequency system made by Medtronic (Minneapolis, MN); all other systems, including implantable pulse generators made by Medtronic, as well as devices made by Advanced Neuromodulation Systems (ANS, Plano, TX) and Advanced Bionics (Sylmar, CA), are used for PNS on an off-label basis.

Resurgence of the PNS approach may be credited to pioneering work of Weiner and Reed ${ }^{34}$ who described the percutaneous technique of electrode insertion in the vicinity of the occipital nerves to treat occipital neuralgia. Soon after, Slavin and Burchiel ${ }^{11,35}$ described use of this technique in both occipital and trigeminal areas, and thereafter the approach was modified by many implanters in term of the electrode type, insertion procedure, indications, and the like. ${ }^{36-61}$

The procedure was not limited to the upper neck and face area, and reports have detailed use of PNS in other parts of the body. For example, percutaneously inserted PNS electrodes were used for control on inguinal pain after herniorrhaphy, ${ }^{62}$ and paraspinal electrodes have been used for treatment of low back pain and sacroiliac pain, ${ }^{63}$ thoracic postherpetic pain, ${ }^{64}$ and coccygodynia. ${ }^{65}$

\section{INDICATIONS}

The usual indications for PNS for neuropathic pain are very similar to those for SCS procedures. The pain has to be chronic, severe, negatively affecting patient's functionality, and refractory to usual medical treatments, including medications, physical therapy, and less invasive interventions such as local anesthetic and sympathetic blocks, application of transcutaneous electrical nerve stimulation (TENS), or injections of botulinum toxin preparations-if these interventions are even considered by the treating physicians.

For the purposes of this article, neuropathic pain is broadly defined as "pain initiated or caused by a primary lesion or dysfunction in the nervous system." $" 66$ This broad definition includes, among other syndromes, such debatable nosological conditions as fibromyalgia, migraines, and coccygodynia.

For classic indications in treatment of neuropathic pain, the nerve involvement is usually suggested by concordant sensory loss, partial or complete, and may be confirmed by a local anesthetic block. This approach has been recommended for treatment of occipital neuralgia, trigeminal neuropathic pain in infraorbital and supraorbital distribution, and inguinal pain in postherniorrhaphy pain syndromes, although, as far as we know, there are no published data about any predictive value of blocks on PNS success. Notably, experience with TENS does not have any predictive value for PNS whatsoever, and a patient's failure to improve with TENS should not stand in the way of trying PNS for pain control (as the author knows from personal experience).

A somewhat different approach is chosen in treatment of emerging indications, such as refractory migraines and fibromyalgia, when there is no obvious injury to the underlying peripheral nerve and the usefulness of diagnostic nerve blocks is rather doubtful. The same holds true for conditions that probably represent a combination of neuropathic and nociceptive pain, such as axial back and neck pain.

Two other criteria are considered before implantation of a PNS system: the patient's psychological evaluation and results of a short-term trial with externalized electrodes. Both steps are borrowed from the standard approach to SCS. Details of the psychological evaluation and their predictive values in SCS were recently reviewed by Doleys. ${ }^{67}$ Outpatient stimulation trial is also a routine step in SCS surgical procedure, and the trial length usually varies between 2 and 14 days. Usually, a $50 \%$ improvement in pain intensity serves as a cutoff limit for considering the trial successful. In some places, patient satisfaction with pain relief (even if pain intensity decrease was less than 50\%) justifies proceeding with permanent implantation. 
In terms of specific indications, there are at least 10 distinct pain conditions for which PNS have been reported: 1) postherpetic neuralgia ${ }^{40,45,64}$;2) post-traumatic or postsurgical neuropathic pain that is related to underlying dysfunction of particular nerves, including the infraorbital, supraorbital, or occipital nerves ${ }^{45,48,52}$; 3) classic migraine, transformed migraine presenting with occipital pain and discomfort, and hemicrania continua $^{39,43,46,47,53,54,56,61}$; 4) occipital neuralgia or cervicogenic occipital pain ${ }^{34,38,47,49,51}$; 5) complex regional pain syndrome ${ }^{28,30,68}$;6) cluster headaches ${ }^{54,58,59,69}$; 7) chronic daily headaches $\left.{ }^{39,53,60} ; 8\right)$ inguinal pain after herniorrhaphy ${ }^{62}$;9) coccygodynia ${ }^{65}$; and 10) fibromyalgia. ${ }^{57,70}$

Due to the relatively simple and nontraumatic nature of PNS, the list of contraindications is short and is based predominantly on commonsense considerations. For example, PNS would be contraindicated in patients with bleeding disorders and active anticoagulation that cannot be stopped for a few days close to the time of the surgical procedure; in patients with active infection, particularly if there is bacteremia or direct involvement of the surgical region; in patients with major cognitive impairment, untreated depression, or malingering; and in patients with unsuccessful PNS trial. In addition, given that no devices on the market today have been cleared for routine MRI testing, those patients who require follow-up MRI studies (e.g., patients with tumors) should not be implanted with PNS.

\section{SURGICAL TECHNIQUE}

Hardware for PNS is usually implanted with a straightforward set of guidelines. the electrode (lead) is implanted in the vicinity of the stimulated nerve. The approach may include either direct exposure of the nerve, ${ }^{32}$ so that the electrode may be placed next to it (or even wrapped around it, similar to vagal nerve stimulation system ${ }^{7,8,71}$ ), or percutaneous electrode implantation through a needle inserted perpendicular to the nerve course. ${ }^{34,48,52,59}$ Somewhat intermediate to these two approaches is the technique of surgical lead insertion toward the nerve without actual nerve exposure. ${ }^{44,47,49,58,61}$

The electrode is then anchored to prevent future migration or displacement. In most cases, the anchors are placed over the electrode stem (in the case of wire-type electrodes) or its tail (in the case of surgical leads or paddles) and sutured to nearby firm and relatively immobile tissue, the fascia or periosteum. Depending on the area of stimulation, this may be done either in the incision itself (in the occipital area, for example) or at a distance from the insertion site, to avoid cosmetic disfigurement (as in infraorbital and supraorbital electrodes, where the anchors are placed in a separate incision behind the ipsilateral ear).

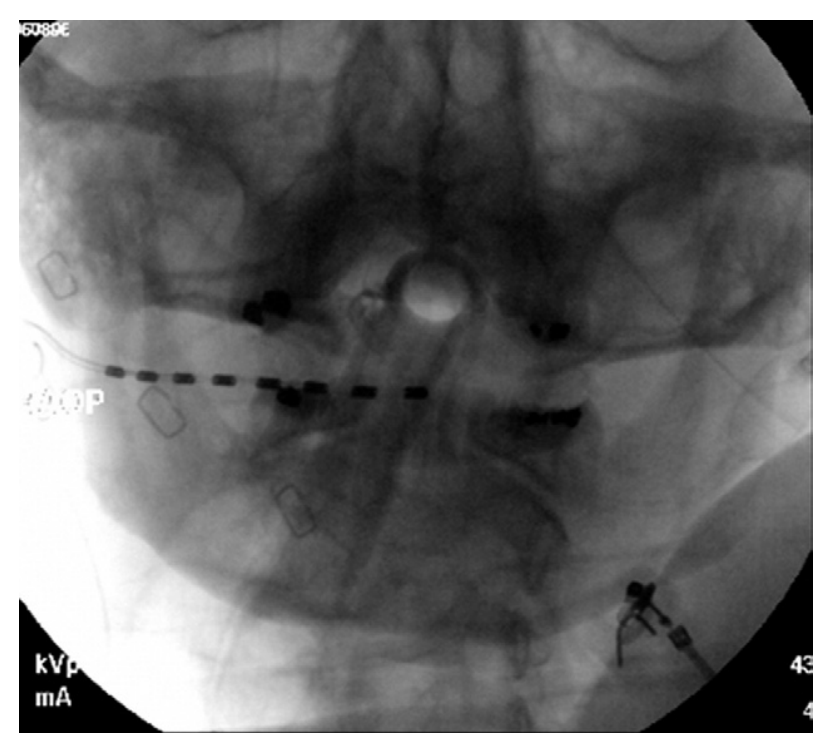

FIG. 1. Anteroposterior radiograph of a unilateral 8-contact occipital nerve stimulation electrode. The electrode is inserted in a lateral-to-medial direction, with the entry point behind the ear, aiming toward the midline and projecting onto the arch of $\mathrm{C} 1$.

One or more electrodes are inserted for the trial in sterile conditions either under local anesthesia or under sedation augmented by infiltration of the insertion site with local anesthetic. Because the procedure is short and the surgical site is quite superficial, general anesthesia is almost never needed.

The direction of electrode insertion may be chosen based on the implanter's preference. For example, at my institution we routinely insert electrodes from lateral to medial not only in the supraorbital and infraorbital regions (where it is probably the only way to put them) but also in the occipital area ${ }^{51,52,55}$; others prefer to insert electrodes from medial to lateral. ${ }^{41,43}$ Standard 4-, 8-, or even 16-contact electrodes ${ }^{61}$ are used (FIGS. 1-5); the electrodes are passed in the epifascial plane under the skin but above the muscles. Our general approach is to have the electrode cross the path of the nerve chosen as a stimulation target. As long as this nerve happens to be either under one of the electrode's contacts, or between the two contacts, the stimulation can be steered toward it in order to get adequate coverage. For the trial insertion, we do not implant any deep anchors or extensions. The electrodes are sutured to the skin with plastic anchors and fine nylon, and a strain-relief loop is created around the insertion site to avoid inadvertent electrode pullout.

The electrodes are almost always inserted under fluoroscopic guidance. In treatment of craniofacial pain, standard landmarks are used for the insertion: the infraorbital foramen and the floor of the orbit for the infraorbital nerve; the supraorbital groove or foramen and the supraorbital ridge for the supraorbital nerve; and the $\mathrm{C} 1$ arch and radiographic midline for the occipital nerves. In the beginning, we tested each patient for stim- 


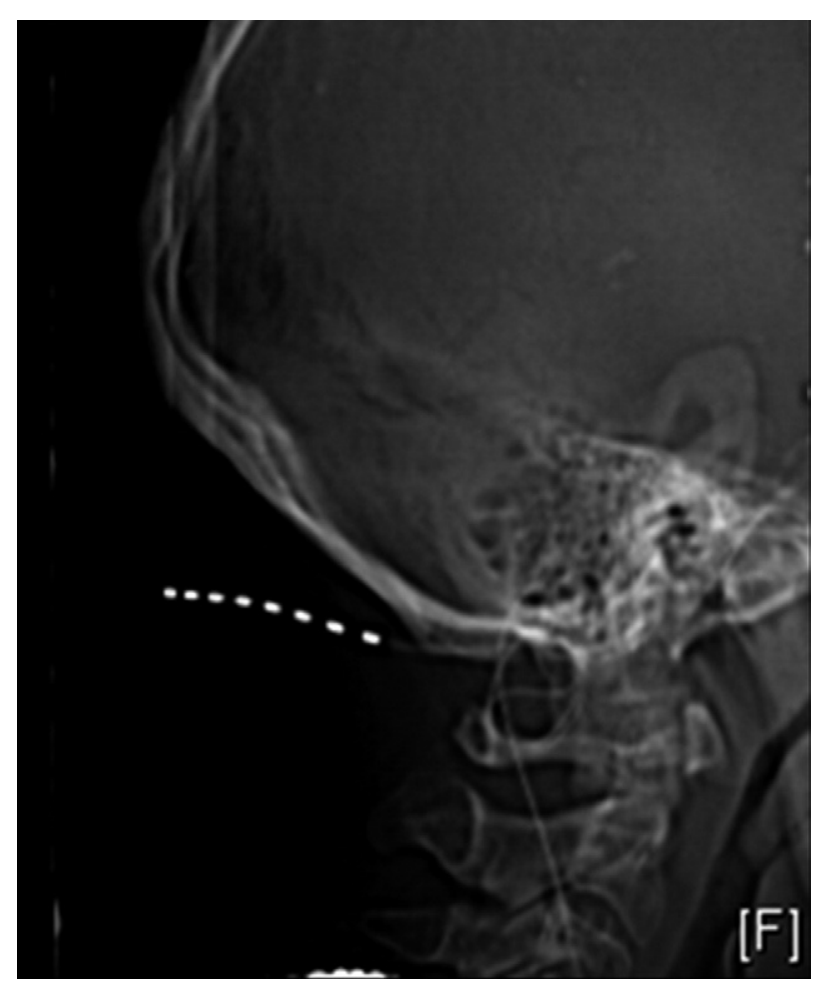

FIG. 2. Lateral radiograph of 8-contact occipital nerve stimulation electrode. Note the epifascial position of the electrode in suboccipital region.

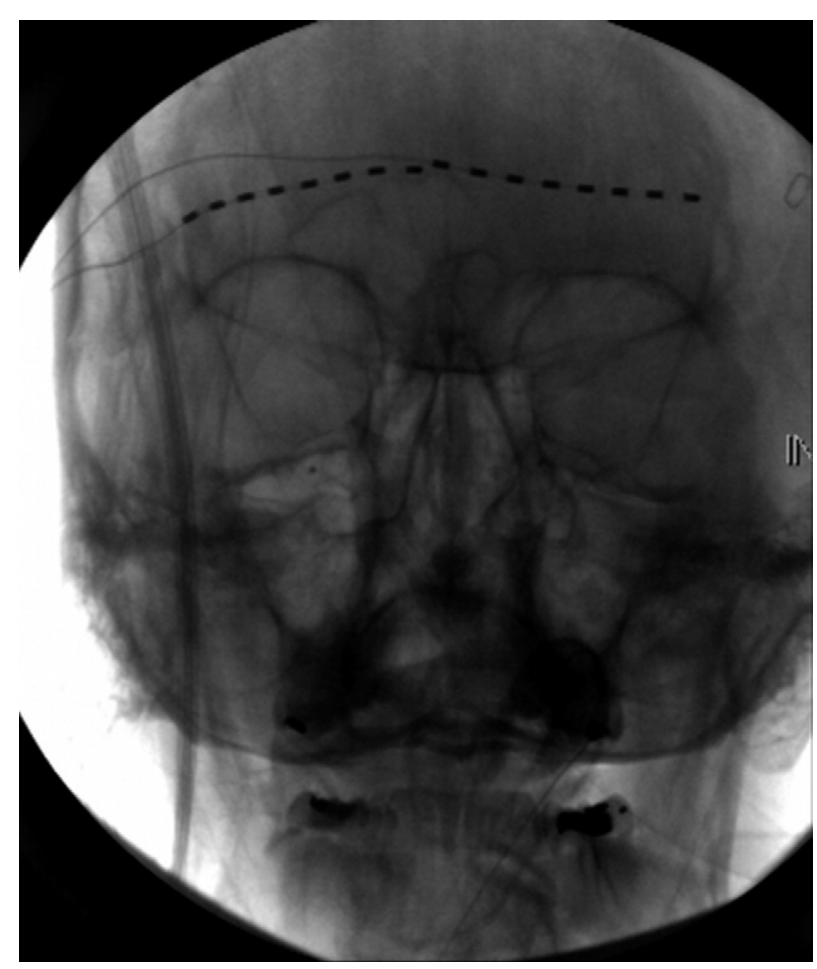

FIG. 4. Anteroposterior radiograph of bilateral 8-contact supraorbital nerve stimulation electrodes. Both supraorbital and supratrochlear nerves may be captured with this electrode position.

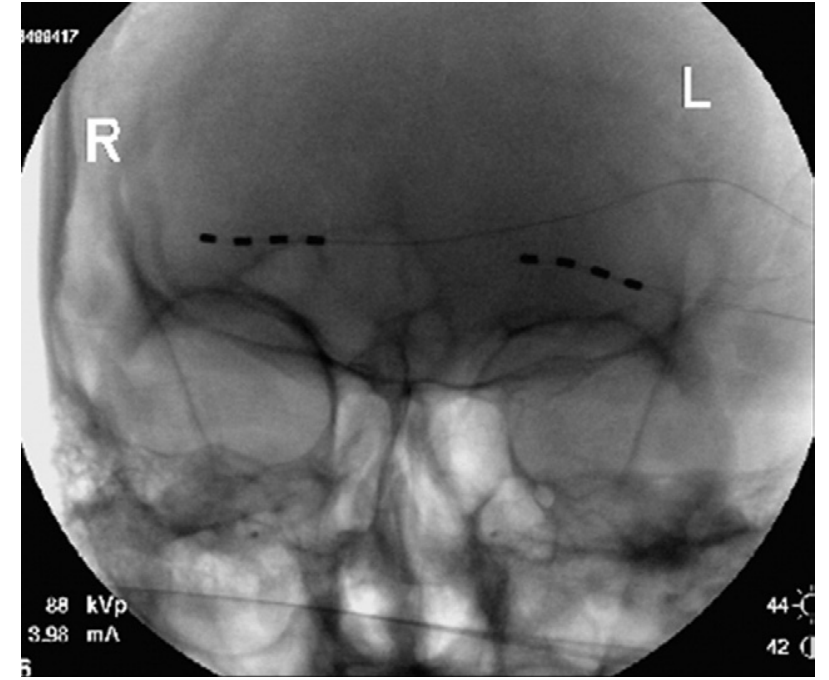

FIG. 3. Anteroposterior radiograph of bilateral 4-contact supraorbital nerve stimulation electrodes. Both electrodes are tunneled to the left side, above the ear and toward the mastoid prominence, where the anchors are placed.

ulation-induced paresthesias in the operating room, so that the position of the electrode could be adjusted if needed. Lately, however, we rely exclusively on anatomical electrode positioning, given the high reliability in getting appropriate coverage. This has resulted in significant improvement in patient comfort, associated with the deeper sedation that may now be used because the patient's cooperation is no longer needed.

The electrode is covered with sterile dressing and attached to the external stimulation system, the initial programming is performed to produce adequate paresthesias in the painful area, the patient is instructed on adjustment

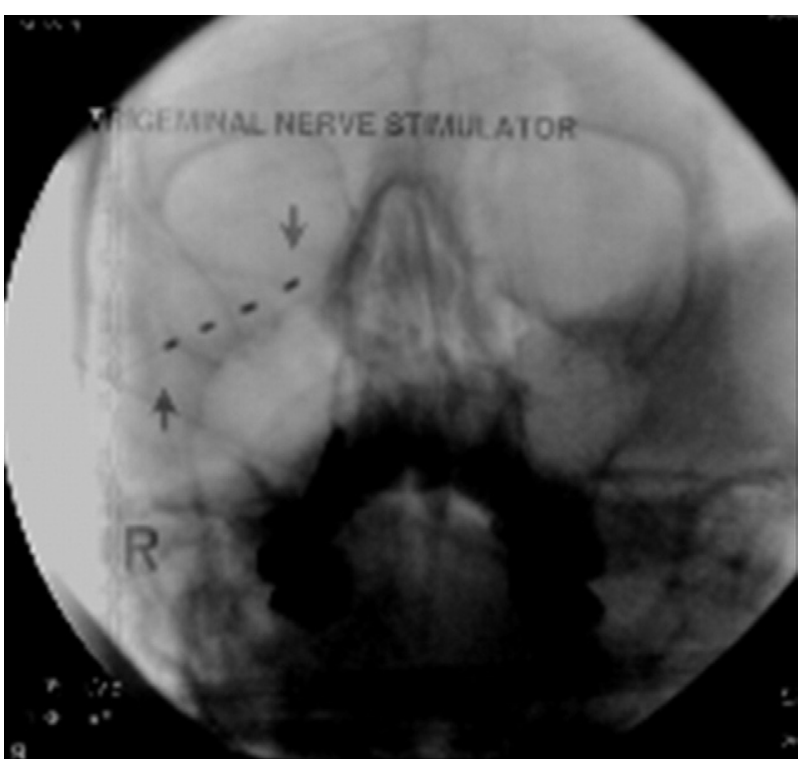

FIG. 5. Anteroposterior radiograph of unilateral 4-contact infraorbital nerve stimulation electrode. The right infraorbital nerve may be captured by stimulation through the two most medial contacts. 
of the stimulator depending on activity and pain level, and antibiotics are prescribed for the duration of trial to avoid development of superficial infection (although this particular step is not supported by any clinical evidence).

Once the trial is completed, the temporary system is replaced with a permanent one. We prefer to remove the temporary electrode in the operating room after confirming its position with fluoroscopy and then, after it has been removed, insert a brand new permanent electrode that is then connected either directly to the generator or to an extension cable that connects to the generator.

The electrodes that we use are cylindrical wire-type (such as Quad, Octad, Quad Plus, or Quad Compact, from Medtronic; Qattrode, Octrode, or Axxess, from ANS; and Linear, from Advanced Bionics). Other groups reported using plate-type electrodes (also known as a paddle-type) (Resume, Resume II, or Resume TL, from Medtronic; Artisan, from Advanced Bionics) for stimulation of the occipital nerves. Implantation of such electrodes may be preceded by a trial with wire-type electrodes $^{49}$ or the trial may be done with a plate-type electrode connected to a temporary extension. ${ }^{47}$ In all cases, the electrodes are placed over the course of the peripheral nerve that supplies the painful area and may be involved in the generation of pain.

The electrodes or extension cables are tunneled toward the generator pocket. The tunneling step is quite painful and, in the author's practice, necessitates the use of general anesthesia. Location of this pocket is chosen based upon the patient's and surgeon's preference. Placement of the generator into the gluteal area, ${ }^{49,50}$ abdominal wall, ${ }^{38,44}$ or infraclavicular areas ${ }^{34,45,47,48,51,55,58}$ has been described. In our opinion, the infraclavicular area (routinely used for placement of DBS generators) is the preferred location for both trigeminal and occipital nerve stimulation systems. We recently presented our analysis of clinical experience of patients with infraclavicular generators, having found an extremely high level of patient satisfaction with this particular location. ${ }^{72}$

Independent of location, the pocket should satisfy certain requirements: it has to be deep enough to avoid hardware erosion; it should not be too deep to interfere with reprogramming or, in the case of rechargeable devices, regular charging; and it should be located in relatively immobile region, because the hardware may fail if subjected to repetitive mechanical stress.

A completely different setup is related to the use of a new and revolutionary device that integrates the generator and electrode into a single, unique apparatus. ${ }^{73}$ The device is called BION (Advanced Bionics), and already, several reports on its clinical use appear in the literature, ${ }^{54,56,74}$ although at writing the device itself has not yet received formal FDA approval. BION is a miniature, leadless, implantable neurostimulator that is designed to be implanted through a small incision, as part of a min- imally-invasive procedure. Because the stimulating electrodes are mounted directly on the neurostimulator, the potential complications associated with the use of lead (migration, disconnection, etc.) are avoided. The device currently being tested is cylinder shaped and measures $3.3 \mathrm{~mm}$ in diameter and $27 \mathrm{~mm}$ in length. It has a cathode on the tip of the stimulator and an anode on its distal surface; it contains a programming and telemetry module and a rechargeable battery. BION allows for the delivery of a wide range of stimulation parameters, with a pulse width of up to 1000 microseconds, a stimulation rate of up to $1000 \mathrm{~Hz}$, and an electrical current amplitude of up to $12 \mathrm{~mA}$. Similar to other devices on the market today, BION is programmed by trained clinicians; a remote control, given to the patient, allows adjustment of the stimulation parameters within a pre-set range. The charging process takes less than two hours; the interval between charging depends on device usage and ranges from daily to every other week, with total battery-life expectation of up to 20 years. $^{75}$

\section{RESULTS AND FUTURE DIRECTIONS}

Thus far, the use of PNS for neuropathic pain has been associated with consistently positive results. ${ }^{53-60,62-64}$ With the one exception of postherpetic trigeminal neuralgia, which has shown only minor improvement in less than half of the patients, ${ }^{45}$ the other indications have either shown themselves to respond to PNS or are currently investigated in prospective fashion.

The older and more established indications, such as post-traumatic and postsurgical neuropathy, occipital neuralgia and complex regional pain syndromes, are very likely to be overshadowed by relatively new indications for PNS, such as migraines and daily headaches, cluster headaches, and fibromyalgia. Even if the effectiveness of PNS for newer indications is less prominent than it is for older and more established ones, the significantly higher prevalence of these newly investigated conditions is likely to further raise interest in PNS in the spectrum of pain-relieving interventions. Obviously, the low invasiveness of PNS, its reversibility, testability and adjustability make it a preferred choice, particularly in comparison with more destructive surgical options, but given the need for implanted hardware and the current high cost of the devices, undoubtedly more studies and larger numbers of patients will be required before PNS is accepted by the medical and third-party-payer communities.

The complication rate for PNS is generally low, but both minor and major complications have been reported, including local infections, hardware erosions, component disconnections, electrode fractures and displacements, ${ }^{32,48,51,55}$ and even sepsis. ${ }^{18,22}$ The complications of perineural fibrosis, described in the past with the use 
of plate or wraparound electrodes, ${ }^{18,24,33}$ are essentially unheard of with the current use of modern wire-type electrodes. Most complications require system revision or replacement; lasting side effects are overall unlikely.

The mechanism of PNS is still largely unknown. Several animal studies have suggested explanations that are related to direct excitation of central pain-processing system and increase in the excitability of the system $^{76,77}$; limited human research has indicated activation of the dorsal rostral pons, anterior cingulate cortex, and cuneus in response to PNS in suboccipital area. ${ }^{46}$ Better understanding of PNS mechanism may result in refinement of surgical indications, individual tailoring of appropriate treatment approach, and perhaps optimization of the hardware choice.

Development of special devices for PNS is yet another potential direction of progress in this rapidly growing area. New electrodes with different spacing options and lower profile may be particularly useful for PNS. Significant research in the area of nerve-electrode interface is currently taking place, ${ }^{78}$ but the devices for PNS have not been developed or approved for widespread clinical use. It is possible that newly developed electrodes will be used not only for PNS in the strict sense of its definition but also in the neighboring area of stimulation of spinal nerves ${ }^{79}$ and gasserian ganglion. ${ }^{80}$ Undoubtedly, $\mathrm{BION}^{73,75}$ and similar devices, dedicated to PNS, may broaden the indications and further decrease the rate of complications and side effects. Acquiring approval for these devices to be used for PNS procedures may in turn facilitate the acceptance of the approach and better reimbursement of those procedures that are done at present only under research protocols or on an off-label basis.

Future research and growing clinical experience will help in identifying the best candidates for PNS, choosing the best procedure and best hardware for each individual patient, and defining adequate expectations for patients and pain specialists. The opportunities for growth are endless-it appears that the current state of PNS represents only a tip of the iceberg, and its full role in the pain management continuum is still to be discovered.

\section{REFERENCES}

1. Beemer GH, Reeves JH, Bjorksten AR. Accurate monitoring of neuromuscular blockade using a peripheral nerve stimulator: a review. Anaesth Intensive Care 1990;18:490-496.

2. Rowlee SC. Monitoring neuromuscular blockade in the intensive care unit: the peripheral nerve stimulator. Heart Lung 1999;28: 352-364.

3. Chervin RD, Guilleminault C. Diaphragm pacing for respiratory insufficiency. J Clin Neurophysiol 1997;14:369-377.

4. Donaldson Nde N, Rushton DN, Perkins TA, Wood DE, Norton J, Krabbendam AJ. Recruitment by motor nerve root stimulators: significance for implant design. Med Eng Phys 2003;25:527-537.

5. Popovic MR, Popovic DB, Keller T. Neuroprostheses for grasping. Neurol Res 2002;24:443-452.

6. Graupe D. An overview of the state of the art of noninvasive FES for independent ambulation by thoracic level paraplegics. Neurol Res 2002;24:431-442.
7. Groves DA, Brown VJ. Vagal nerve stimulation: a review of its applications and potential mechanisms that mediate its clinical effects. Neurosci Biobehav Rev 2005;29:493-500.

8. Walsh SP, Kling MA. VNS and depression: current status and future directions. Expert Rev Med Devices 2004;1:155-160.

9. Oerlemans DJ, van Kerrebroeck PE. Sacral nerve stimulation for neuromodulation of the lower urinary tract. Neurourol Urodyn 2007 Jun 11 [Epub ahead of print].

10. Holzer B, Rosen HR, Novi G, Ausch C, Hölbling N, Schiessel R. Sacral nerve stimulation for neurogenic faecal incontinence. $\mathrm{Br} \mathbf{J}$ Surg. 2007;94:749-753.

11. Slavin KV, Burchiel KJ. Peripheral nerve stimulation for painful nerve injuries. Contemp Neurosurg 1999;21(19):1-6.

12. Melzack RA, Wall PD. Pain mechanisms: a new theory. Science 1965;150:971-979.

13. Wall PD, Sweet WH. Temporary abolition of pain in man. Science 1967;155:108-109.

14. White JC, Sweet WH. Pain and the neurosurgeon: a forty-year experience. Springfield, IL: Thomas, 1969:894-899.

15. Shelden CH. Depolarization in the treatment of trigeminal neuralgia. Evaluation of compression and electrical methods; clinical concept of neurophysiological mechanism. In: Knighton RS, Dumke PR, editors.Pain. Boston: Little, Brown, 1966:373-386.

16. Cauthen JC, Renner EJ. Transcutaneous and peripheral nerve stimulation for chronic pain states. Surg Neurol 1975;4:102-104.

17. Kirsch WM, Lewis JA, Simon RH. Experiences with electrical stimulation devices for the control of chronic pain. Med Instrum 1975;9:217-220.

18. Picaza JA, Cannon BW, Hunter SE, Boyd AS, Guma J, Maurer D. Pain suppression by peripheral nerve stimulation: II. Observations with implanted devices. Surg Neurol 1975; 4:115-126.

19. Campbell JN, Long DM. Peripheral nerve stimulation in the treatment of intractable pain. J Neurosurg 1976;45:692-699.

20. Sweet WH. Control of pain by direct stimulation of peripheral nerves. Clin Neurosurg 1976;23:103-111.

21. Nashold BS Jr, Mullen JB, Avery R. Peripheral nerve stimulation for pain relief using a multicontact electrode system: technical note. J Neurosurg 1979;51:872-873.

22. Law JD, Sweet J, Kirsch WM. Retrospective analysis of 22 patients with chronic pain treated by peripheral nerve stimulation. J Neurosurg 1980;52:482-485.

23. Long DM, Erickson D, Campbell J, North R. Electrical stimulation of the spinal cord and peripheral nerves for pain control: a 10-year experience. Appl Neurophysiol 1981;44:207-217.

24. Nashold BS Jr, Goldner JL, Mullen JB, Bright DS. Long-term pain control by direct peripheral nerve stimulation. J Bone Joint Surg Am 1982;64:1-10.

25. Waisbrod H, Panhans C, Hansen D, Gerbeshagen HU. Direct nerve stimulation for painful peripheral neuropathies. J Bone Joint Surg Br 1985;67:470-472.

26. Long DM. Stimulation of the peripheral nervous system for pain control. Clin Neurosurg 1986;33:323-343.

27. Iacono RP, Linford J, Sandyk R. Pain management after lower extremity amputation. Neurosurgery 1987;20:496-500.

28. Racz GB, Browne T, Lewis R Jr. Peripheral stimulator implant for treatment of causalgia caused by electrical burns. Tex Med 1988; $84: 45-50$

29. Heavner JE, Racz G, Diede JM. Peripheral nerve stimulation: current concepts. In: Waldman SD, Winnie AP, editors. Interventional pain management, 1st ed. Philadelphia: W.B. Saunders, 1996:423-425.

30. Hassenbusch SJ, Stanton-Hicks M, Schoppa D, Walsh JG, Covington EC. Long-term results of peripheral nerve stimulation for reflex sympathetic dystrophy. J Neurosurg 1996;84:415-423.

31. Stanton-Hicks M, Salamon J. Stimulation of the central and peripheral nervous system for the control of pain. J Clin Neurophysiol 1997;14:46-62.

32. Shetter AG, Racz GB, Lewis R, Heavner JE. Peripheral nerve stimulation. In: North RB, Levy RM, editors. Neurosurgical management of pain. New York: Springer, 1997:261-270.

33. Nielson KD, Watts C, Clark WK. Peripheral nerve injury from implantation of chronic stimulating electrodes for pain control. Surg Neurol 1976;5:51-53. 
34. Weiner RL, Reed KL. Peripheral neurostimulation for control of intractable occipital neuralgia. Neuromodulation 1999;2:217-221.

35. Slavin KV, Burchiel KJ. Use of long-term nerve stimulation with implanted electrodes in the treatment of intractable craniofacial pain. J Neurosurg 2000;92:576.

36. Weiner RL. The future of peripheral nerve stimulation. Neurol Res 2000;22:299-304.

37. Lou L. Uncommon areas of electrical stimulation. Curr Rev Pain 2000;4:407-412.

38. Hammer M, Doleys DM. Perineuromal stimulation in the treatment of occipital neuralgia: a case study. Neuromodulation 2001; $4: 47-51$.

39. Weiner RL, Aló KM, Reed KL, Fuller ML. Subcutaneous neurostimulation for intractable C-2-mediated headaches. J Neurosurg 2001;94:398A (abstract).

40. Dunteman E. Peripheral nerve stimulation for unremitting ophthalmic postherpetic neuralgia. Neuromodulation 2002;5:32-37.

41. Aló KM, Holsheimer J. New trends in neuromodulation for the management of neuropathic pain. Neurosurgery 2002;50:690-704.

42. Weiner RL. Peripheral nerve neurostimulation. Neurosurg Clin N Am 2003;14:401-408.

43. Popeney CA, Aló KM. Peripheral neurostimulation for the treatment of chronic, disabling transformed migraine. Headache 2003; 43:369-375.

44. Jones RL. Occipital nerve stimulation using a Medtronic Resume II $^{\circledR}$ electrode array. Pain Physician 2003;6:507-508.

45. Johnson MD, Burchiel KJ. Peripheral stimulation for treatment of trigeminal postherpetic neuralgia and trigeminal posttraumatic neuropathic pain: a pilot study. Neurosurgery 2004;55:135-142.

46. Matharu MS, Bartsch, Ward N, Frackowiak RSJ, Weiner R, Goadsby PJ. Central neuromodulation in chronic migraine patients with suboccipital stimulators: a PET study. Brain 2004;127:220230.

47. Oh MY, Ortega J, Bellotte JB, Whiting DM, Aló K. Peripheral nerve stimulation for the treatment of occipital neuralgia and transformed migraine using a C1-2-3 subcutaneous paddle style electrode: a technical report. Neuromodulation 2004;7:103-112.

48. Slavin KV, Wess C. Trigeminal branch stimulation for intractable neuropathic pain: a technical note. Neuromodulation 2005;8:7-13.

49. Kapural L, Mekhail N, Hayek SM, Stanton-Hicks M, Malak O. Occipital nerve electrical stimulation via the midline approach and subcutaneous surgical leads for treatment of severe occipital neuralgia: a pilot study. Anesth Analg 2005;101:171-174.

50. Rodrigo-Royo MD, Azcona JM, Quero J, Lorente MC, Acín P, Azcona J. Peripheral neurostimulation in the management of cervicogenic headaches: four case reports. Neuromodulation 2005;4: 241-248.

51. Slavin KV, Nersesyan H, Wess C. Peripheral neurostimulation for treatment of intractable occipital neuralgia. Neurosurgery 2006;58: 112-119.

52. Slavin KV, Nersesyan H, Wess C. Treatment of neuropathic craniofacial pain using peripheral nerve stimulation approach. In: Meglio M, Krames ES, editors. Proceedings of the 7th INS Meeting of the International Neuromodulation Society: Rome, Italy, June 10-13, 2005. Bologna: Medimond International Proceedings, 2005:77-80.

53. Weiner RL. Occipital neurostimulation for treatment of intractable headache syndromes. Acta Neurochir Suppl 2007;97:129-133.

54. Schwedt TJ, Dodick DW, Trentman TL, Zimmerman RS. Occipital nerve stimulation for chronic cluster headache and hemicrania continua: pain relief and persistence of autonomic features. Cephalalgia 2006;26:1025-1027.

55. Slavin KV, Colpan ME, Munawar N, Wess C, Nersesyan H. Trigeminal and occipital peripheral nerve stimulation for craniofacial pain: a single-institution experience and review of the literature. Neurosurg Focus 2006;21(6):E5.

56. Rogers LL, Swidan S. Stimulation of the occipital nerve for the treatment of migraine: current state and future prospects. Acta Neurochir Suppl 2007;97(Pt 1):121-128.

57. Thimineur M, De Ridder D. C2 area neurostimulation: a surgical treatment for fibromyalgia. Pain Med 2007;8:639-646.
58. Magis D, Allena M, Bolla M, De Pasqua V, Remacle JM, Schoenen J. Occipital nerve stimulation for drug-resistant chronic cluster headache: a prospective pilot study. Lancet Neurol 2007; 6:314-321.

59. Burns B, Watkins L, Goadsby PJ. Treatment of medically intractable cluster headache by occipital nerve stimulation: long-term follow-up of eight patients. Lancet 2007;369:1099-1106.

60. Schwedt TJ, Dodick DW, Hentz J, Trentman TL, Zimmerman RS Occipital nerve stimulation for chronic headache: long-term safety and efficacy. Cephalalgia 2007;27:153-157.

61. Hagen JE, Bennett DS. Occipital nerve stimulation for treatment of migraine. Practical Pain Management 2007;7(6):43-45,56.

62. Stinson LW Jr, Roderer GT, Cross NE, Davis BE. Peripheral subcutaneous electrostimulation for control of intractable postoperative inguinal pain: a case report series. Neuromodulation 2001; 4:99-104.

63. Paicius RM, Bernstein CA, Lempert-Cohen C. Peripheral nerve field stimulation for the treatment of chronic low back pain: preliminary results of long-term follow-up: a case series. Neuromodulation 2007;10:279-290.

64. Yakovlev AE, Peterson AT. Peripheral nerve stimulation in treatment of intractable postherpetic neuralgia. Neuromodulation 2007; 10:373-375.

65. Kothari S. Neuromodulatory approaches to chronic pelvic pain and coccygodynia. Acta Neurochir Suppl 2007;97(Pt 1):365-371.

66. Merskey H, Bogduk N. Classification of chronic pain: descriptions of chronic pain syndromes and definitions of pain terms, 2nd ed. Seattle, WA: IASP Press, 1994.

67. Doleys DM. Psychological factors in spinal cord stimulation therapy: brief review and discussion. Neurosurg Focus 2006;21(6):E1.

68. Monti E. Peripheral nerve stimulation: a percutaneous minimally invasive approach. Neuromodulation 2004;7:193-196.

69. Leone M, Franzini A, Cecchini AP, Broggi G, Bussone G. Stimulation of occipital nerve for drug-resistant chronic cluster headache. Lancet Neurol 2007;6:289-291.

70. Slavin KV. Peripheral neurostimulation in fibromyalgia: a new frontier?! Pain Med 2007;8:621-622.

71. Mauskop A. Vagus nerve stimulation relieves chronic refractory migraine and cluster headaches. Cephalalgia 2005;25:82-86.

72. Syed M, Slavin KV. Infraclavicular generator placement for neurostimulation: are the patients satisfied? In: Meglio M, Krames ES, editors. Proceedings of the 7th INS Meeting of the International Neuromodulation Society: Rome, Italy, June 10-13, 2005. Bologna: Medimond International Proceedings, 2005:81-84.

73. Loeb GE, Peck RA, Moore WH, Hood K. BION system for distributed neural prosthetic interfaces. Med Eng Physics 2001;23:9-18.

74. Groen J, Amiel C, Bosch JL. Chronic pudendal nerve neuromodulation in women with idiopathic refractory detrusor overactivity incontinence: results of a pilot study with a novel minimally invasive implantable mini-stimulator. Neurourol Urodyn 2005;24: $226-230$

75. Carbunaru R, Whitehurst T, Jaax K, Koff J, Makous J. Rechargeable battery-powered Bion microstimulators for neuromodulation. Conf Proc IEEE Eng Med Biol Soc 2004;6:4193-4196.

76. Bartsch T, Goadsby PJ. Stimulation of the greater occipital nerve induces increased central excitability of dural afferent input. Brain 2002;125:1496-1509.

77. Le Doaré K, Akerman S, Holland PR, et al. Occipital afferent activation of second order neurons in the trigeminocervical complex in rat. Neurosci Lett 2006;403:73-77.

78. Navarro X, Krueger TB, Lago N, Micera S, Stieglitz T, Dario P. A critical review of interfaces with the peripheral nervous system for the control of neuroprosthesis and hybrid bionic systems. J Periph Nerv Syst 2005;10:229-258.

79. Haque R, Winfree CJ. Spinal nerve root stimulation. Neurosurg Focus 2006;21(6):E4.

80. Machado A, Ogrin M, Rosenow JM, Henderson JM. A 12-month prospective study of gasserian ganglion stimulation for trigeminal neuropathic pain. Stereotact Funct Neurosurg 2007;85:216-224. 